\title{
Is there an association between spatial accessibility of outpatient care and utilization? Analysis of gynecological and general care
}

\author{
Ulrike Stentzel $^{1^{*}} \mathbb{D}$, Jeanette Bahr ${ }^{1,2}$, Daniel Fredrich ${ }^{1}$, Jens Piegsa', Wolfgang Hoffmann ${ }^{1}$ \\ and Neeltje van den Berg ${ }^{1}$
}

\begin{abstract}
Background: In rural regions with a low population density, distances to health care providers as well as insufficient public transport may be barriers for the accessibility of health care. In this analysis it was examined whether the accessibility of gynecologists and GPs, measured as travel time both by car and public transport has an influence on the utilization of health care in the rural region of Western Pomerania in Northern Germany.

Methods: Utilization data was obtained from the population based Study of Health in Pomerania (SHIP). Utilization was operationalized by the parameter "at least one physician visit during the last 12 months". To determine travel times by car and by public transport, network analyses were conducted in a Geographic Information System (GIS). Multivariate logistic regression models were calculated to identify determinants for the utilization of gynecologists and GPs.

Results: There is no significant association between the accessibility by car or public transport and the utilization of gynecologists and GPs. Significant predictors for the utilization of gynecologists in the regression model including public transport are age (OR 0.960, 95\% Cl 0.950-0.971, $p<0.0001)$, social class (OR 1.137, 95\% Cl 1.084-1.193, p<0.0001) and having persons $\geq 18$ years in the household (OR 2.315, 95\% Cl 1.116-4.800, $p=0.0241$ ).
\end{abstract}

Conclusions: In the examined region less utilization of gynecologists is not explainable with long travel times by car or public transport.

Keywords: Accessibility, Utilization, GP, Gynecologist, GIS

\section{Background}

In sparsely populated rural regions the spatial distribution of healthcare providers cannot be as dense as in urban regions. A possible consequence could be that the spatial accessibility of medical facilities [1] affects the utilization of health services. Spatial accessibility refers to the ease to reach e.g. medical services and facilities $[2,3]$. The definition of ease includes both the geographic distance that must be overcome and the needed time to do so. Large distances to healthcare [4-11] as well as insufficient public transport [12-14] may be barriers for access

\footnotetext{
* Correspondence: ulrike.stentzel@uni-greifswald.de

'Institute for Community Medicine, University Medicine Greifswald,

Ellernholzstraße 1-2, 17487 Greifswald, Germany

Full list of author information is available at the end of the article
}

to and utilization of healthcare facilities. Different approaches have been used to study the accessibility. Some studies draw on physician density $[15,16]$, some on distances assessed in self-reports [4, 13], some took distances from web resources which provide these information [6]. Simplified methods include calculation of straight-line distances (Euclidian) in Geographic Information Systems (GIS) $[9,12,17]$. However, several studies used exacter geographic methods $[5,7,8,11,15,18-20]$. Most GIS allow performing network analyses that calculate distance in length measurement units or in time units based on routable road network data. Commonly the above mentioned analyses confined to accessibility by motorized individual transport (cars or other motorized vehicles). The motorized individual transport plays the essential part in

(c) The Author(s). 2018 Open Access This article is distributed under the terms of the Creative Commons Attribution 4.0 International License (http://creativecommons.org/licenses/by/4.0/), which permits unrestricted use, distribution, and 
traffic in rural regions, but not everyone in Germany has access to a private car [21]. The population in Germany's rural regions is often older and the regional deprivation is higher [22, 23]. Hence, vulnerable parts of the population might be dependent on public transport. However, in German rural regions public transport usually is orientated to school traffic [24]. Therefore, accessibility by public transport should be considered [25]. Only a few studies considered accessibility by public transport. This is mostly due to the lack of appropriate public transport data for the use in GIS. Studies that included public transport used either self-reported data or defined the quality of accessibility by the frequency (high versus low) of public transport services or whether or not a section of the rural road network was bus serviced at least every hour during daytime $[8,14$, 20].

The objective of this analysis was to examine whether accessibility by car and by public transport is associated with the utilization of outpatient general practitioners (GP) and gynecologists as an example for specialized physicians.

In contrast to many other countries, the people in Germany have the free choice of doctor, which is incorporated into law. People with a disease or a health problem normally have to consult an outpatient general practitioner (GP) at first. For particular medical problems, the patients will be referred to an outpatient medical specialist. In some cases, e.g. for routine examinations at gynecologists, patients can also go directly to medical specialists without referral [26].

The study region was the region Western Pomerania in the northeast of Germany. This region has 322,863 inhabitants, a mean population density of 77 inhabitants per $\mathrm{km}^{2}(12 / 2010$ [27]) and is classified as a rural area of lower population density [28]. The research question was that the utilization of GPs and gynecologists is lower with longer travel time to the nearest GP/gynecologist.

\section{Methods \\ Data}

For reasons of comparability, both analyses were focused only on women. Utilization, age, socioeconomic data and persons in the household $\geq 18$ years were retrieved from the 5-year follow-up (SHIP-1) of the populationbased epidemiologic cohort study "Study of Health in Pomerania" (SHIP) which was performed in 2002-2006 [29]. SHIP-1 contains in total 3300 participants. Thereof, 1172 female participants were included in the analysis. The participants were of age 25-88. Therefore, only the utilization of adults is considered. In SHIP-1 the utilization of GPs and gynecologists during the twelve months prior to the data assessment was obtained in a standardized face-to-face interview. Participants self- reported at least one visit in the 12 months prior to the assessment. The Winkler social class index was used to represent social status $[30,31]$. The social class index is a multi-dimensional index that considers income, education, and professional status [32-34].

Persons in the household $\geq 18$ years were included, because they are old enough to have a driver's license and might be able to give a ride. A comprehensive description of the SHIP study is published by John et al. [29].

\section{Calculation of distances and travel times}

The spatial accessibility of the physician practices was operationalized by calculating travel times between the residential addresses of each participant and the nearest practices by car and by public transport. For both analyzes was an underlying assumption that the participants use the respective transportation mode and that they visit the closest practice.

Geographical coordinates of the residential addresses of the female participants of SHIP-1 and the locations of the practices of 248 GPs and 38 gynecologists in the study region were calculated in a geographic information system (GIS) (ESRI ${ }^{\oplus}$ ArcGIS ${ }^{\mathrm{sm}} 10.0$ Esri Inc., Redlands/ California (USA)). Additionally, 93 GPs and 9 gynecologists in a $12 \mathrm{~km}$ buffer zone around the study region were included. The addresses of the practices were retrieved from the physician directory of the Association of Statutory Health Insurance Physicians of the federal states of Mecklenburg-Western Pomerania and Brandenburg.

\section{Travel times by car}

The distances between the residential addresses of the participants and the physician practices and the travel times by car were calculated using routable digital street data (Dplus, Logiball, Herne, Germany). The calculation of distances and travel times was conducted with ArcGIS, using the software extension Network Analyst which allows network-based spatial analysis. Not considered were delays due to traffic jams, construction sites etc.

\section{Travel times by public transport}

The accessibility of the practices by public transport was calculated on the basis of timetables of busses and trains. Geographic coordinates of bus and train stops were partly delivered by public transportation services and partly assessed in the field by project staff with GPS devices.

The calculation of the accessibility by public transport included some assumptions:

- The appointment with the physician was set at Tuesday, 11 am during school times, because public 
transport is closely aligned with the transport of school children.

- The pedestrian speed was set at $4 \mathrm{~km} / \mathrm{h}$ for SHIP-1 participants under 51 years, $3 \mathrm{~km} / \mathrm{h}$ for $51-69$ year old participants and $2 \mathrm{~km} / \mathrm{h}$ for participants of 70 years and older.

- Foot walks between the patients homes and the practices and between the homes of the patients and the bus and train stops were limited to a maximum length of $1000 \mathrm{~m}$.

- Foot walks between the bus and train stops and the practices were limited to a maximum length of $500 \mathrm{~m}$.

- Foot walks needed to change between busses and/or trains were limited to a maximum length of $250 \mathrm{~m}$.

- The journey back home after the physician appointment was set to start at $12 \mathrm{pm}$ and had to be finished the same day before midnight.

The duration of the appointment with the physician was not included in the travel time. The calculated travel time was the total travel time of the roundtrip.

The calculation of the travel times by public transport was conducted on the basis of the Dijkstra algorithm $[35,36]$ using a self-developed network analysis software [25]. The shortest travel time (in minutes) was determined along the nodes of the network and their connecting edges. The footpaths were calculated with the network Analyst in ArcGIS.

\section{Statistical analysis}

Multivariate logistic regression analyses were conducted to identify determinants for the utilization of gynecologists and GPs. Outcome of the regression analyses was the utilization of the gynecologist and/or GP in the 12 months prior to the assessment (operationalized as at least one visit in the 12 months prior to the assessment). Age was included as a metric variable. The travel times were included as a metric variable in minutes by car and as a categorical variable (categories: $\leq 60 \mathrm{~min}(\mathrm{~min}),>60$ $-\leq 120 \mathrm{~min},>120$ - $\leq 180 \mathrm{~min},>180 \mathrm{~min}$, no connection at all) by public transport. The social class index is calculated additively as a point sum score [37] and was also included as a metric varaible. The higher the score the higher the social status. SAS 9.3 (c) 2002-2010 (SAS Institute Inc., Cary, NC, USA) was used to perform all statistical analyses.

\section{Results}

SHIP-1 has 3300 participants in total. The flowchart in Fig. 1 shows the number of included and excluded participants in this analysis and the reasons for exclusion.

\section{Utilization}

Figure 2 shows the utilization of gynecologists and GPs by women in SHIP-1 by age group during the 12 months prior to the assessment. The utilization of GPs increases with increasing age whereas the utilization of gynecological medical care is high in young age groups and decreases with increasing age.

\section{Spatial accessibility \\ General medical care}

Figure 3 shows the results of the geographical analysis of the accessibility of GPs by car. Table 1 shows the number of patients in the different travel time categories. More than $90 \%$ of the participants have a travel time of 5 min or less.

The accessibility with regard to public transport differs from the accessibility by car (Fig. 4). $83 \%$ of the participants $(n=968)$ of the study participants have access to a GP within one hour by public transport (Table 2) whereas $2.5 \%$ of the participants $(n=29)$ have no access with public transport. This means that they can't travel to the nearest GP and travel back within one day. The distance to the practices does not play a major role. Accessibility rather depends on the connection to the public transport network.

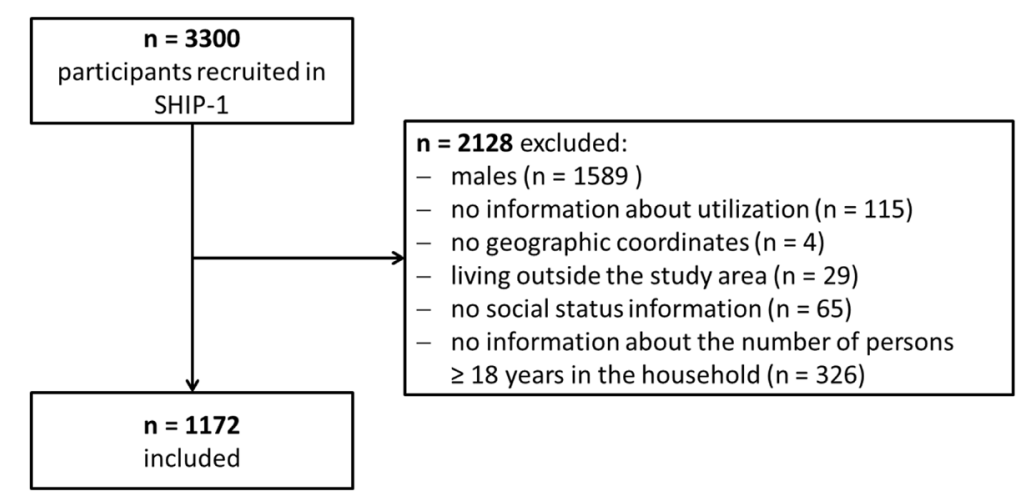

Fig. 1 Number of patients included in the analysis 


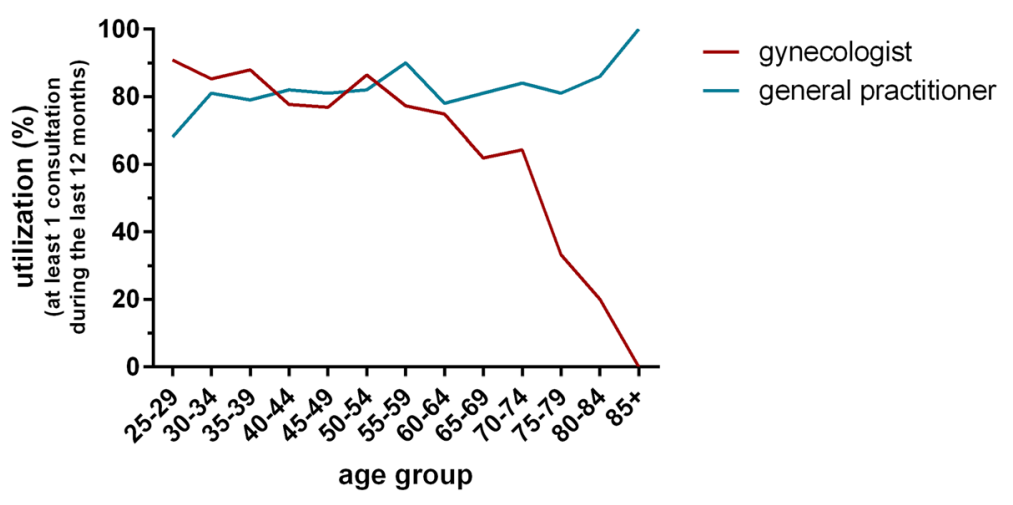

Fig. 2 Utilization of gynecologists and GPs by women in SHIP-1 in the 12 months prior to the assessment (at least one visit)

\section{Gynecological practices}

Compared to GPs the number of the gynecologists as an example for specialized physicians is much lower and their spatial distribution in the region is less dense. This is reflected in longer travel times by car (Fig. 5 and Table 3). Although the gynecological practices are concentrated in the larger towns, just $63.6 \%$ of the participants have a travel time of 5 min or less.

The accessibility by public transport is also poorer for gynecologists than for GPs (Fig. 6 and Table 4). Just 62.
$5 \%$ of the participants have access within one hour. The participants without access by public transport to the nearest gynecologists are the same as in the analysis of the accessibility of the GPs.

\section{Logistic regression models \\ General practitioners}

Regarding GPs, only the social class index was found to be a significant determinant for utilization in both models. If the social class index increases by 1 , the

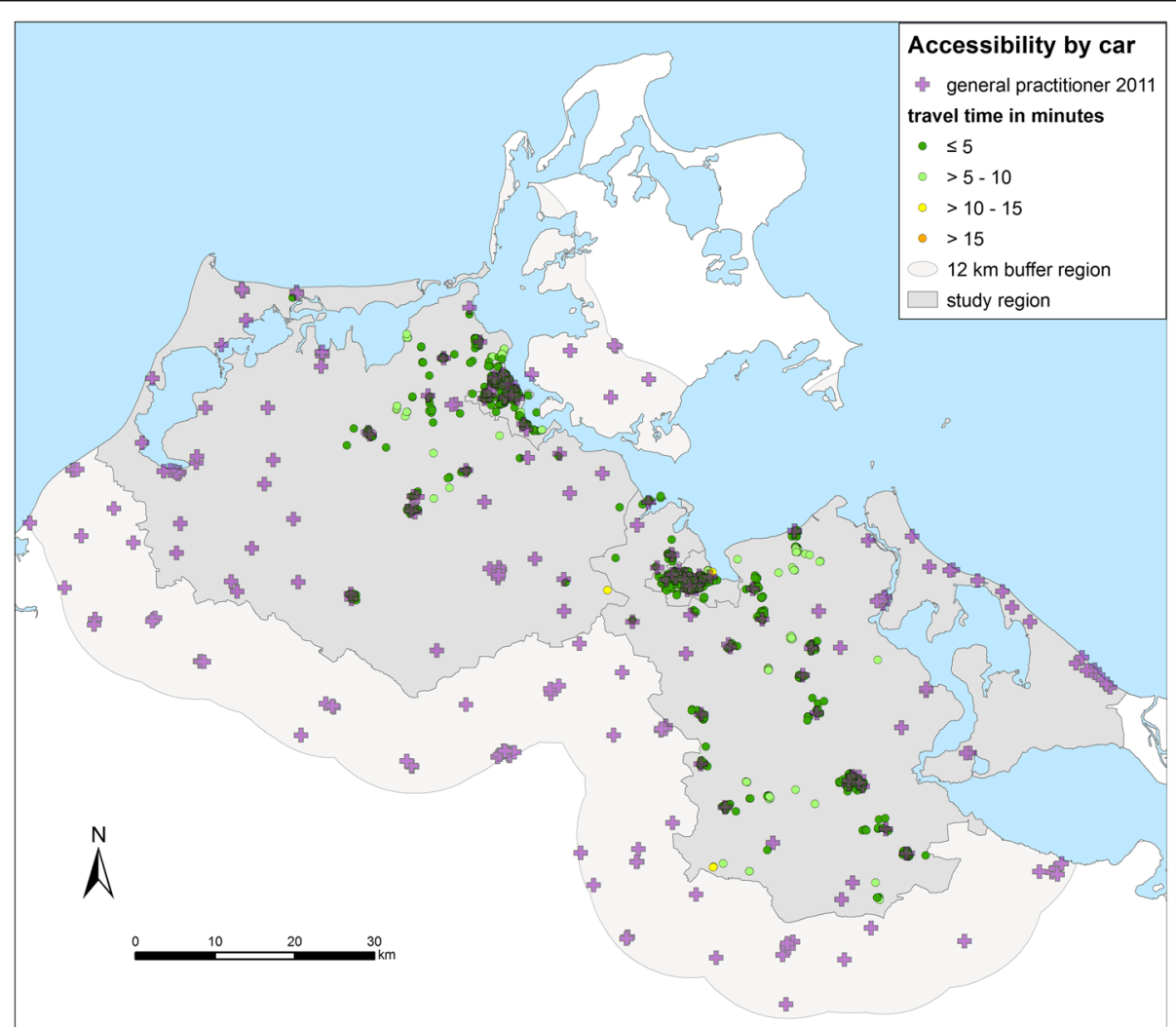

Fig. 3 Accessibility of GPs by car. Travel times from the homes of the patients to the nearest practice in minutes (one way) in the region Western Pomerania in the northeast of Germany (source: author's own figure/map) 
Table 1 Accessibility of GPs by car: number and proportion of participants, mean and standard deviation (SD) of travel time to the nearest practice

\begin{tabular}{lllll}
\hline $\begin{array}{l}\text { Travel time } \\
\text { in 5-min- } \\
\text { categories }\end{array}$ & Participants & & & \\
\cline { 2 - 5 } & number & $\%$ & mean & SD \\
\hline$\leq 5$ min & 1079 & 92.1 & 1.3 & 1.0 \\
$>5-10$ min & 87 & 7.4 & 7.1 & 1.7 \\
$>10-15$ min & 6 & 0.5 & 11.3 & 0.9 \\
\hline
\end{tabular}

probability of utilization decreases by a factor of 0.947 (by car, Table 5) or 0.948 (by public transport, Table 6). The odds for utilization of GPs increase with increasing age and with increasing travel time, but the coefficients are not statistically significant. However, regarding travel time a trend is clearly present. The odds for utilization decrease with persons in the household $\geq 18$ years, but again the association does not reach the level of statistical sign (Table 5 and Table 6).

\section{Gynecological care}

Regarding the travel time by car, the probability of utilization of a gynecologist decreases when the travel time by car is higher, but this difference is not statistically significant (Table 7). With respect to public
Table 2 Accessibility of GPs by public transport: number and percentage of participants, mean and Standard deviation (SD) of travel time to the nearest practice

\begin{tabular}{llllll}
\hline $\begin{array}{lllll}\text { Travel time in } \\
\begin{array}{l}\text { 60-min- } \\
\text { kategories }\end{array}\end{array}$ & \multicolumn{2}{l}{ Participants } & & \multicolumn{2}{l}{ Travel time (minutes) } \\
& number & Percent (\%) & & mean & SD \\
\hline$\leq 60$ & 968 & 82.59 & & 17.2 & 11.8 \\
$>60-120$ & 77 & 6.57 & & 96.3 & 17.3 \\
$>120-180$ & 87 & 7.42 & & 146.5 & 16.8 \\
$>180$ & 11 & 0.94 & & 198.7 & 10.2 \\
No connection & 29 & 2.47 & & - \\
\hline
\end{tabular}

transport, the probability of utilization decreases when the travel time by public transport is above $60 \mathrm{~min}$ compared to travel times less or equal than $60 \mathrm{~min}$ (Table 8), but the coefficient is not statistically significantly different from the Null and the confidence interval (CI) is large.

The odds for utilization declines in both models when age is increasing (travel time by car and by public transport). In contrast, the odds for utilization increase with increasing social class index. The odds for utilizing a gynecologist are two times higher if the participants live together with persons $\geq 18$ years in their household (Table 7 and Table 8).

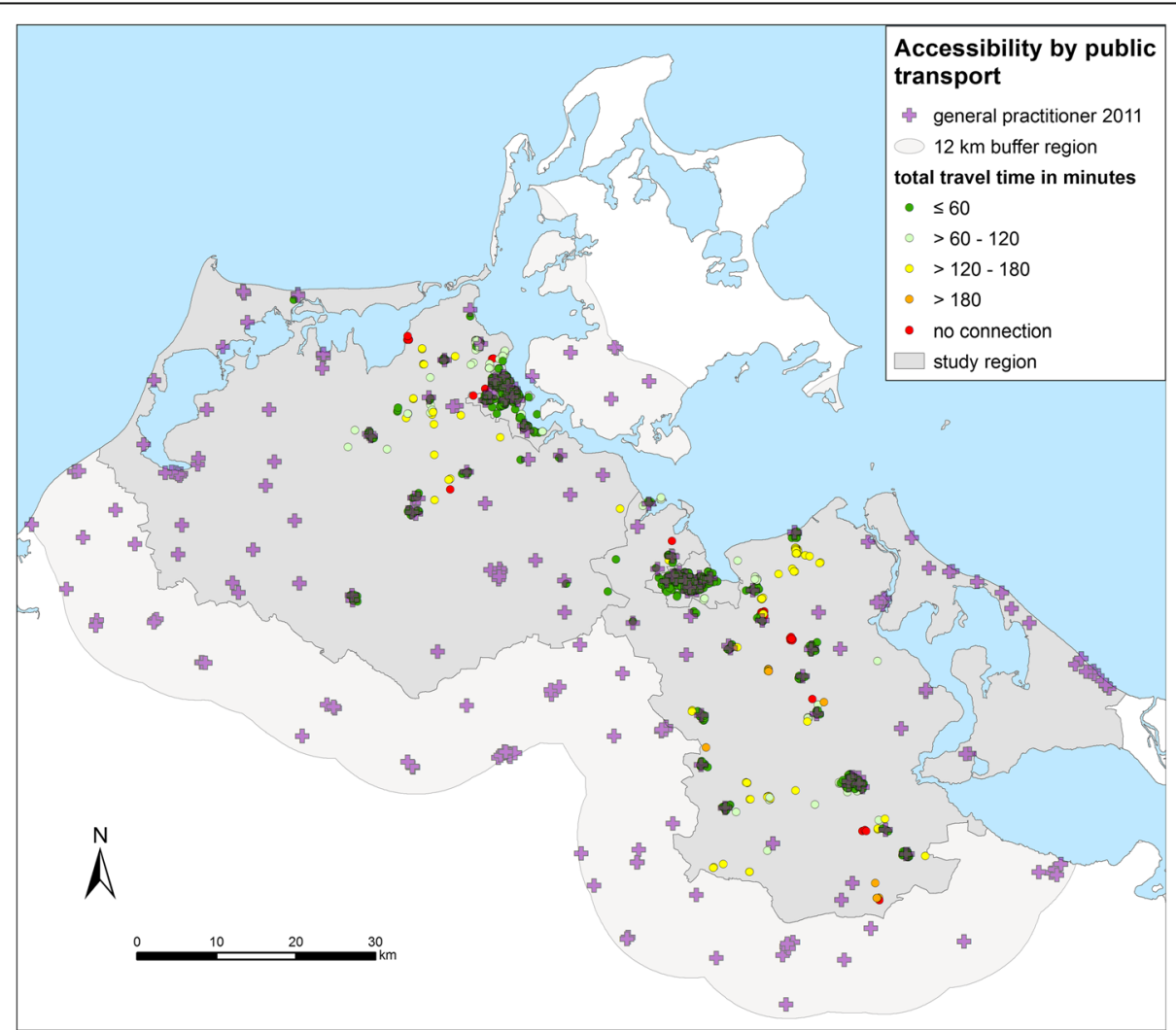

Fig. 4 Accessibility of GPs by public transport from the homes of the patients to the nearest practice in minutes (round trip) in the region Western Pomerania in the northeast of Germany (source: author's own figure/map) 


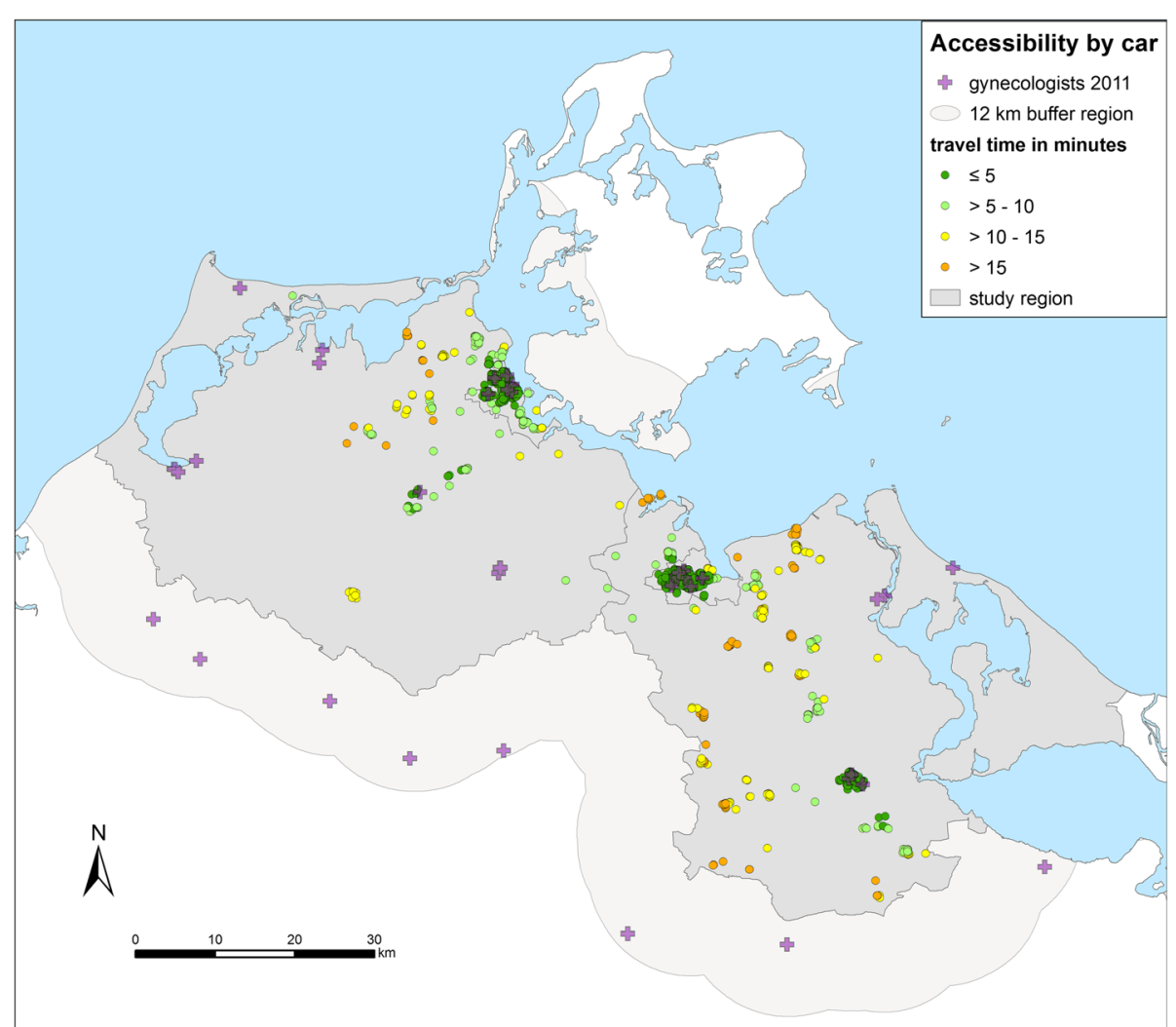

Fig. 5 Accessibility of gynecologists by car. Travel times from the homes of the patients to the nearest practice in minutes (one way) in the region Western Pomerania in the northeast of Germany (source: author's own figure/map)

\section{Discussion}

The hypothesis of this analysis was that the utilization of GP and medical specialist care (here: gynecologists) would be influenced by the travel times to the practices. A trend can be seen, but the results show, that neither travel time by car nor by public transport is significantly associated with whether or not a gynecologist or GP was consulted in the previous 12 months. Some international studies found associations between spatial accessibility and utilization or issues like regular check-up visits. Jones et al. [20] and Celaya et al. [17] found associations between tumor stage at diagnosis of breast cancer and increasing travel time to GP and other medical services. Jones et al. could prove for breast and colorectal cancers

Table 3 Accessibility of gynecologists by car: number and percentage of participants, mean and standard deviation (SD) of travel times to the nearest practice

\begin{tabular}{lllll}
\hline $\begin{array}{l}\text { Travel time } \\
\text { in 5-min- } \\
\text { categories }\end{array}$ & Participants & & & \\
\cline { 2 - 5 } & number & $\%$ & mean & SD \\
\hline$\leq 5$ min & 745 & 63.57 & 1.8 & 1.0 \\
$>5-10$ min & 165 & 14.08 & 7.9 & 1.5 \\
$>10-15$ min & 169 & 14.42 & 12.5 & 1.6 \\
$>15$ min & 93 & 7.94 & 17.3 & 2.7 \\
\hline
\end{tabular}

that the availability of public transport was associated with a reduced risk of late stage diagnosis. The authors assume that because of longer travel times patients were less likely to make doctor's appointments compared to people living closer to the providers [20]. Arcury et al. [8] found that greater distance resulted in fewer regular check-up visits while distance was not significant in determining the number of chronic care and acute care visits. More important than distance for adherence to regular check-up visits was holding a driver's license. Users of chronic care visits showed a significantly higher number of uses of shared rides and public transport. Even though these authors determined that distance was not a major barrier to chronic care they conclude that a lack of access to transportation may lead to less utilization of medical care [8]. Rocha et al. examined the role of public transport in accessibility to emergency dental care in Melbourne. They revealed that a similar number of patients came from areas with and without access to public transport. At least for emergency dental care access to public transport had no effects on utilization [14]. A study among American Indian and Alaska Natives in the United States showed that the geographic location of patients, their potential access to cancer screening services and utilization of cancer 


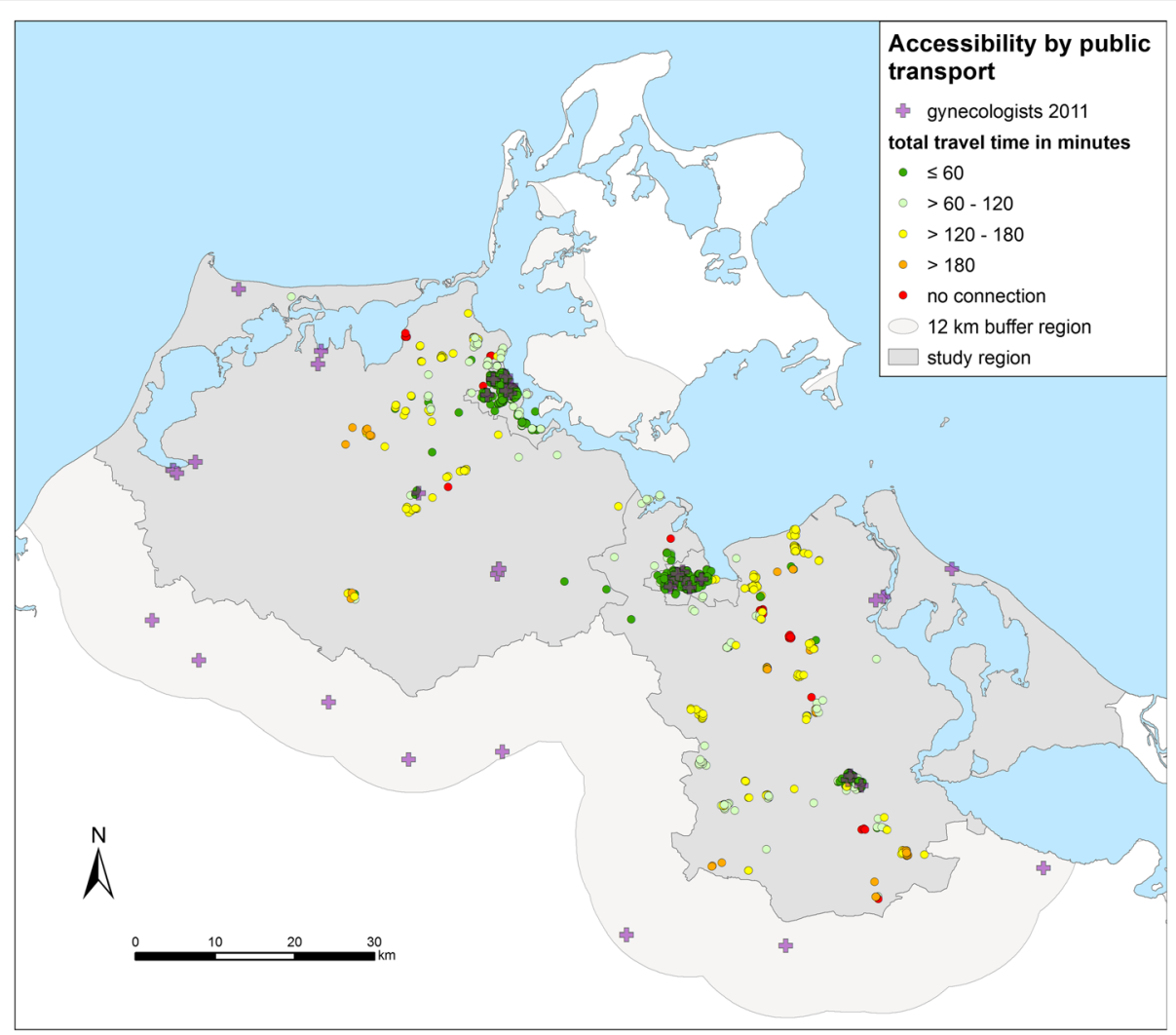

Fig. 6 Accessibility of gynecologists by public transport from the homes of the patients to the nearest practice in minutes (round trip) in the region Western Pomerania in the northeast of Germany (source: author's own figure/map)

screening are all interrelated [19]. The authors showed that the proportion of cancer screened females dropped significantly with a higher degree of rurality and greater distance to the nearest provider.

Two other studies came to the result that distance to the closest mammography facility is indeed a significant risk factor for predicting advanced stage diagnosis in breast cancer [38, 39]. A Norwegian study could show an association between increasing distance to the primary care clinic and lower utilization of out-of-hours services except for telephone consultations [11]. Another study found that a reduction of the distance or the travel

Table 4 Accessibility of gynecologists by public transport: number and percentage of participants, mean and standard deviation (SD) of travel time to the nearest practice

\begin{tabular}{lllll}
\hline $\begin{array}{l}\text { Travel time in } \\
\begin{array}{l}\text { 60-min- } \\
\text { categories }\end{array}\end{array}$ & Participants & & & \\
\cline { 2 - 5 } & number & $\%$ & mean & SD \\
\hline S60 min & 733 & 62.5 & 25.4 & 12.6 \\
$>60-120$ min & 184 & 15.7 & 93.2 & 15.3 \\
$>120-180$ min & 182 & 15.5 & 146.6 & 16.2 \\
$>180$ min & 44 & 3.8 & 204.1 & 18.6 \\
No connection & 29 & 2.5 & - & - \\
\hline
\end{tabular}

time to a hospital leads to an increase of the utilization of hospitals by COPD patients [40]. The results of all these studies indicate that travel time has an influence on the utilization of health care providers. In contrast, Tarlov et al. [41] found no significant association between distance to mammography facilities and the tumor stage at diagnosis.

The actual use of public transport in our study region is rather low. A survey of the National Association of Statutory Health Insurance Physicians in 2010 found that only $8 \%$ of the respondents used public transport [42]. A recent survey in an adjacent and very similar rural region in Germany determined that $67.7 \%$ of the participants used the car to get to a doctor's appointment and $26 \%$ used the bus [43].

As a consequence of the low population density, the public transport network is often poor in rural regions, which in turn tends to reduce the number of users [44]. Where public transport is inadequate, a large proportion of peripherally resident people apparently are used to drive by car or find other solutions like rideshares to run their errands. This seems to include also their visits to GPs and specialist physicians. Having persons $\geq 18$ years in the household was a significant determinant for the utilization of gynecologists. In our analysis this suggests 
Table 5 Multivariate logistic regression analysis of the influence of travel time by car on the utilization of GPs, $n=1172$ participants (SAS proc. logistic)

\begin{tabular}{|c|c|c|c|c|c|c|}
\hline \multirow[t]{2}{*}{ Predictor } & \multirow[t]{2}{*}{$\beta$} & \multirow[t]{2}{*}{ SE $\beta$} & \multirow[t]{2}{*}{$p(a=0.05)$} & \multirow[t]{2}{*}{$e^{\beta}$ (odds ratio) } & \multicolumn{2}{|l|}{$\mathrm{Cl}$} \\
\hline & & & & & $2.5 \%$ & $97.5 \%$ \\
\hline Travel time by car (min.) & 0.0828 & 0.0446 & .063 & 1.09 & 0.995 & 1.186 \\
\hline Age & 0.00756 & 0.00585 & .197 & 1.01 & 0.996 & 1.019 \\
\hline Social class index ${ }^{a}$ & -0.0543 & 0.0264 & .040 & 0.95 & 0.899 & 0.997 \\
\hline $\begin{array}{l}\text { Persons } \geq 18 \text { years in the } \\
\text { household (yes/no) }\end{array}$ & -0.3214 & 0.4576 & .482 & 0.73 & 0.296 & 1.778 \\
\hline
\end{tabular}

Abbreviations: $\beta$, regression coefficient; $S E$, standard error; Cl confidence interval; ${ }^{a}$ Winkler social class index (Winkler, 1998, Winkler and Stolzenberg, 1999$)$

that for older women living more remote, the utilization of gynecologic facilities may depend on the opportunity to get rides to the gynecologist. Travel time is obviously not decisive to explain the lower utilization of gynecologists in the study region.

Living with other adults in the household was not a significant predictor for the utilization of GPs. It may generally be easier to reach the GP because of the larger geographic density of GP-practices.

The results show that the utilization of gynecologists significantly increased with higher social class index. Higher education might foster higher health competence and awareness for health checks [45]. Data from the cross-sectional German Health Servey (Gesundheit in Deutschland aktuell, GEDA) showed an association between low check-up participation and low social status [46]. That study detected that education isn't significantly associated to check-up participation, but occupational status and income are. An evaluation of the German Health Survey in the German federal state North Rhine-Westphalia found that women from the upper class have higher participation rates for cancer screening tests than women from the lower class [47]. On the contrary an evaluation of class-specific utilization of medical services and prevention in Bavaria in the south of Germany did not show differences between socioeconomic classes regarding mammography and other cancer screening tests [48]. Tian et al. tried to identify risk factors for disparities in breast cancer mortality among African-American and Hispanic Women [49]. They concluded that access to mammography facilities does not determine a greater utilization. A lower SES, however, was associated with lower utilization of mammography facilities. This corresponds to our findings regarding the utilization of outpatient gynecological care. Also the fact that the utilization of GPs decreases with higher social class index is corresponding with other studies [50-54].

\section{Limitations and strengths}

The determination of accessibility is based on a range of assumptions. For example it was assumed that patients get treatment from the geographically nearest physician's practice. However, accessibility is not always the determining criterion for the choice of one's doctor. Also qualifications, reputation and recommendation [55] of an individual physician, availability of appointments as

Table 6 Multivariate logistic regression analysis of the influence of travel time with public transport on the utilization of GPS. $n=1172$ participants (SAS proc. logistic)

\begin{tabular}{|c|c|c|c|c|c|c|}
\hline \multirow[t]{2}{*}{ Predictor } & \multirow[t]{2}{*}{$\beta$} & \multirow[t]{2}{*}{ SE $\beta$} & \multirow[t]{2}{*}{$p(a=0.05)$} & \multirow[t]{2}{*}{$e^{\beta}$ (odds ratio) } & \multicolumn{2}{|l|}{$\mathrm{Cl}$} \\
\hline & & & & & $2.5 \%$ & $97.5 \%$ \\
\hline \multicolumn{7}{|c|}{ Travel time with public transport* } \\
\hline no connection & -0.1484 & 0.4566 & .745 & 1.14 & 0.429 & 3.050 \\
\hline$t>180 \mathrm{~min}$ & 0.4343 & 0.8525 & .610 & 2.05 & 0.259 & 16.227 \\
\hline $120 \min <t \leq 180 \min$ & 0.0642 & 0.3473 & .853 & 1.41 & 0.751 & 2.667 \\
\hline $60 \min <t \leq 120 \min$ & -0.0669 & 0.3490 & .848 & 1.24 & 0.655 & 2.353 \\
\hline Age & 0.00720 & 0.00584 & .218 & 1.017 & 0.996 & 1.019 \\
\hline Social class index ${ }^{a}$ & -0.056 & 0.0264 & .043 & 0.95 & 0.900 & 0.998 \\
\hline $\begin{array}{l}\text { Persons } \geq 18 \text { years in the } \\
\text { household (yes } / \text { no) }\end{array}$ & -0.3161 & 0.4573 & .489 & 0.73 & 0.298 & 1.786 \\
\hline
\end{tabular}

*reference travel time by public transport $t \leq 60$ min Abbreviations: $\beta$, regression coefficient; SE, standard error; Cl confidence interval, $t$, travel time; ${ }^{a}$ Winkler social class index (Winkler, 1998, Winkler and Stolzenberg, 1999) 
Table 7 Multivariate logistic regression analysis of the influence of travel time with car on the utilization of gynecologists, $n=1172$ (SAS proc. logistic)

\begin{tabular}{|c|c|c|c|c|c|c|}
\hline \multirow[t]{2}{*}{ Predictor } & \multirow[t]{2}{*}{$\beta$} & \multirow[t]{2}{*}{ SE $\beta$} & \multirow[t]{2}{*}{$p(a=0.05)$} & \multirow[t]{2}{*}{$e^{\beta}$ (odds ratio) } & \multicolumn{2}{|l|}{$\mathrm{Cl}$} \\
\hline & & & & & $2.5 \%$ & $97.5 \%$ \\
\hline Travel time by car (min.) & -0.0160 & 0.0131 & .223 & 0.98 & 0.959 & 1.010 \\
\hline Age & -0.0412 & 0.00573 & .000 & 0.96 & 0.949 & 0.971 \\
\hline Social class index ${ }^{a}$ & 0.1304 & 0.0244 & .000 & 1.14 & 1.086 & 1.195 \\
\hline $\begin{array}{l}\text { Persons } \geq 18 \text { years in the } \\
\text { household (yes/no) }\end{array}$ & 0.8443 & 0.3724 & .023 & 2.32 & 1.121 & 4.826 \\
\hline
\end{tabular}

Abbreviations: $\beta$, regression coefficient; SE, standard error; Cl confidence interval; ${ }^{a}$ Winkler social class index (Winkler, 1998, Winkler and Stolzenberg, 1999$)$

well as other activities of daily life (e.g. work locations) can influence the choice of a doctor [56].

The accessibility by car can be calculated under relatively realistic conditions whereas regarding the public transport accessibility requires several assumptions. These include the length of the foot paths and walking speed. These definitions, in part, determine which patients are assigned to the category "no connection". The doctor's appointment (Tuesday, 11 am during school time) was chosen for all calculations because this was the time with best public transport connections. Both at other times and during the holidays connectivity was found to be lower.

Unfortunately, we did not know whether the participants use the car or public transport. A cross-sectional survey assessed the mobility behavior of people aged 60 years and older in the same region as our study region. $33.7 \%$ of the participants reported, that they usually walk, use a bike, the bus, or other modes of transportation for the study region [57].

Major sickness as a covariate is not considered in the model. Chronic diseases would be a good parameter for the model. The SHIP data does not provide an appropriate variable. Besides all women are recommended to regularly visit a gynecologist for preventative check-ups. Therefore, we accepted this limitation.
The model fit was evaluated with goodness of fit statistic (Hosmer-Lemeshow test). It was computed for all four models. Both models regarding GPs are acceptable models for the data with $p$-values of 0.8273 (car) and 0.9188 (public transport). The p-value of the gynecologists-model are slightly below and above alpha 0.05 with 0.0333 (car) and 0.0547 (public transport). The goodness of fit is marginally to low here.

Strengths of the study are (a) the data from the population based prospective SHIP-cohort and (b) the consideration of real road-networks (including specific speed categories for motorized vehicles as well as for pedestrians), real bus and train schedules and changes of means of transport. Thus, the model uses valid data and depicts the reality in the study region as close as possible.

\section{Conclusions}

This study showed that accessibility is not significantly associated with the utilization of GPs and gynecologists in a rural region of Western Pomerania. Significant predictors for the utilization of gynecologists are social class index and persons $\geq 18$ years living in the household of the participants.

Table 8 Multivariate logistic regression analysis of the influence of travel time with public transport on the utilization of gynecologists. $n=1172$ participants (SAS proc. logistic)

\begin{tabular}{|c|c|c|c|c|c|c|}
\hline \multirow[t]{2}{*}{ Predictor } & \multirow[t]{2}{*}{$\beta$} & \multirow[t]{2}{*}{ SE $\beta$} & \multirow{2}{*}{$\begin{array}{l}p(a \\
= \\
0.05)\end{array}$} & \multirow{2}{*}{$\begin{array}{l}e^{\beta} \\
\text { (odds } \\
\text { ratio) }\end{array}$} & \multicolumn{2}{|l|}{$\mathrm{Cl}$} \\
\hline & & & & & $2.5 \%$ & $97.5 \%$ \\
\hline \multicolumn{7}{|l|}{ Travel time with public transport ${ }^{\mathrm{a}}$} \\
\hline no connection & -0.1518 & 0.3557 & .670 & 0.69 & 0.292 & 1.645 \\
\hline$t>180 \mathrm{~min}$ & -0.2859 & 0.2821 & .311 & 0.61 & 0.310 & 1.185 \\
\hline $120 \min <\mathrm{t} \leq 180 \mathrm{~min}$ & 0.0817 & 0.1844 & .658 & 0.88 & 0.587 & 1.303 \\
\hline $60 \min <t \leq 120 \min$ & 0.1404 & 0.1867 & .452 & 0.93 & 0.619 & 1.389 \\
\hline Age & -0.0405 & 0.00574 & .000 & 0.96 & 0.950 & 0.971 \\
\hline Social class index & 0.1286 & 0.0245 & .000 & 1.14 & 1.084 & 1.193 \\
\hline Persons $\geq 18$ years in the household (yes/no) & 0.8394 & 0.3721 & .024 & 2.32 & 1.116 & 4.800 \\
\hline
\end{tabular}




\section{Abbreviations}

GIS: Geographic information system; GP: General practitioner; SHIP: Study of Health in Pomerania

\section{Acknowledgments}

We would like to thank the data providers of the study: Data from the Study of Health in Pomerania (SHIP) were provided by the Community Medicine Research Alliance, University Medicine Greifswald. The Association of Statutory Health Insurance Physicians Mecklenburg-Western Pomerania provided the location data of the GP and gynecological practices. The regional public transport companies provided time tables. Logiball $\mathrm{GmbH}$ provided digital routable street data.

\section{Funding}

This research did not receive any specific grant from funding agencies in the public, commercial, or not-for-profit sectors.

\section{Availability of data and materials}

The usage of SHIP data must be applied at the transfer office for data and biomaterial management at the University medicine of Greifswald (https:// www.fvcm.med.uni-greifswald.de/dd_service/data_use_intro.php?lang=ger). Data-requests for locations of GPS and gynecologists can be made at the Association of Statutory Health Insurance Physicians Mecklenburg-Western Pomerania (http://www.kvmv.info/).

The licensed routable street data ("DeutschlandPlus") were purchased from Logiball (https://www.logiball.de/index.php/de/).

Time tables for public transport were retrieved from 17 different in the study region operating companies on the basis of project-related requests. If interested, we can make these files available on request.

\section{Authors' contributions}

$\mathrm{WH}$ and NvdB made substantial contributions to conception and design of this study. JB and US participated in the design of the utilization analysis. JP and DF designed and implemented the network-analysis-model for the calculation of the accessibility by public transport. JB performed the statistical and US the geographical analyses. US drafted the manuscript. JP and DF critically revised the manuscript regarding the description of the technical parts of the network application. NvdB, WH and JB critically revised the manuscript. All authors gave approval to the manuscript. NvdB gave final approval for publishing.

\section{Ethics approval and consent to participate}

The SHIP-1 data were requested from the Community Medicine Research Alliance of the University Medicine Greifswald. SHIP-1 was approved by the ethics committee of the University Medicine Greifswald (registration number: III UV 73/01). The approval and the handover of the SHIP-1 data through the Community Medicine Research Alliance include the consent for publication as long as data protection is respected. For the representation of the participants' residences on the maps, the geographical coordinates of the participants were spatially noised to preclude identification of individual participants. After performing the network analyzes, random numbers are generated and added or subtracted to the exact $x$ and $y$ coordinates to pseudonymize the geographic coordinates. This produces incorrect coordinates which lie in a square of $50 \mathrm{~m}$ edge length. Therefore, the identification of the participants' addresses is not possible.

\section{Competing interests}

The authors declare that they have no competing interests.

\section{Publisher's Note}

Springer Nature remains neutral with regard to jurisdictional claims in published maps and institutional affiliations.

\section{Author details}

${ }^{1}$ Institute for Community Medicine, University Medicine Greifswald, Ellernholzstraße 1-2, 17487 Greifswald, Germany. ${ }^{2}$ Clinic and Outpatient Clinic for Internal Medicine C, University Medicine Greifswald, Sauerbruchstraße, Diagnostic Center, 17475 Greifswald, Germany.
Received: 31 July 2017 Accepted: 24 April 2018

Published online: 03 May 2018

\section{References}

1. Focke A. Regionale Leistungs- und Krankenhausplanung. Ein Simulationsmodell auf Basis eines Ameisenalgorithmus. Wiesbaden: Deutscher Universitäts-Verlag/GWV Fachverlage; 2006.

2. Hewko J, Smoyer-Tomic KE, Hodgson MJ. Measuring Neighbourhood spatial accessibility to urban amenities: does aggregation error matter? Environ Plan A. 2002;34(7):1185-206.

3. Mao L, Nekorchuk D. Measuring spatial accessibility to healthcare for populations with multiple transportation modes. Health \& place. 2013;24: 115-22.

4. Smith ML, Dickerson JB, Wendel ML, Ahn S, Pulczinski JC, Drake KN, Ory MG. The utility of rural and underserved designations in geospatial assessments of distance traveled to healthcare services: implications for public health research and practice. J Environ Public Health. 2013;2013:960157.

5. Goodman DC, Fisher E, Stukel TA, Chang C. The distance to community medical care and the likelihood of hospitalization: is closer always better? Am J Public Health. 1997:87(7):1144-50.

6. Sanz-Barbero B, Otero Garcia L, Blasco Hernandez T. The effect of distance on the use of emergency hospital services in a Spanish region with high population dispersion: a multilevel analysis. Med Care. 2012;50(1):27-34.

7. Siegel M, Koller D, Vogt V, Sundmacher L. Developing a composite index of spatial accessibility across different health care sectors: a German example. Health policy (Amsterdam, Netherlands). 2016;120(2):205-12.

8. Arcury TA, Gesler WM, Preisser JS, Sherman J, Spencer J, Perin J. The effects of geography and spatial behavior on health care utilization among the residents of a rural region. Health Serv Res. 2005;40(1):135-55.

9. McKernan SC, Pooley MJ, Momany ET, Kuthy RA. Travel burden and dentist bypass among dentally insured children. J Public Health Dent. 2016;76(3): $220-7$.

10. Weinhold I, Gurtner S. Understanding shortages of sufficient health care in rural areas. Health policy (Amsterdam, Netherlands). 2014;118(2):201-14.

11. Raknes G, Hansen EH, Hunskaar S. Distance and utilisation of out-of-hours services in a Norwegian urban/rural district: an ecological study. BMC Health Serv Res. 2013:13:222.

12. Campbell NC, Elliot AM, Sharp L, Ritchie LD, Cassidy J, Little J. Rural factors and survival from cancer: analysis of Scottish cancer registrations. $\mathrm{Br} \mathrm{J}$ Cancer. 2000;82(11):1863-6.

13. Goins RT, Williams KA, Carter MW, Spencer M, Solovieva T. Perceived barriers to health care access among rural older adults: a qualitative study. The Journal of rural health : official journal of the American Rural Health Association and the National Rural Health Care Association. 2005;21(3):206-13.

14. Rocha CM, Kruger E, McGuire S, Tennant M. Role of public transport in accessibility to emergency dental care in Melbourne, Australia. Australian journal of primary health. 2015;21(2):227-32

15. Vogt $V$, Siegel M, Sundmacher L. Examining regional variation in the use of cancer screening in Germany. Soc Sci Med. 2014;110:74-80.

16. Kopetsch T, Schmitz H. Regional variation in the utilisation of ambulatory services in Germany. Health Econ. 2014;23(12):1481-92.

17. Celaya MO, Rees JR, Gibson JJ, Riddle BL, Greenberg ER. Travel distance and season of diagnosis affect treatment choices for women with early-stage breast cancer in a predominantly rural population (United States). Cancer causes \& control : CCC. 2006;17(6):851-6.

18. Baig K, Shaw-Ridley M, Munoz OJ. Applying geo-spatial analysis in community needs assessment: implications for planning and prioritizing based on data. Evaluation and program planning. 2016:58:42-8.

19. Towne SD Jr, Smith ML, Ory MG. Geographic variations in access and utilization of cancer screening services: examining disparities among American Indian and Alaska native elders. Int J Health Geogr. 2014;13:18.

20. Jones AP, Haynes R, Sauerzapf V, Crawford SM, Zhao H, Forman D. Travel times to health care and survival from cancers in northern England. Eur J Cancer. 2008;44(2):269-74.

21. Dallinger G, Hänsel K, Martin R, Petter M, Habisch R. Datenreport 2013 - Ein Sozialbericht für die Bundesrepublik Deutschland. Bonn: Bundeszentrale für politische Bildung; 2013.

22. Hofmeister C, Maier W, Mielck A, Stahl L, Breckenkamp J, Razum O. Regionale Deprivation in Deutschland: Bundesweite Analyse des Zusammenhangs mit Mortalität unter Verwendung des, German Index of 
Multiple Deprivation GIMD. Gesundheitswesen Bundesverband der Arzte des Offentlichen Gesundheitsdienstes Germany. 2016;17(01):42-8.

23. Kopetsch T, Maier W. Analysis of the association between regional deprivation and utilization: an assessment of need for physicians in Germany. Germany: Gesundheitswesen (Bundesverband der Arzte des Offentlichen Gesundheitsdienstes); 2016.

24. Kraftfahrt-Bundesamt. Kraftfahrzeugbestand nach Kraftsfahrzeugarten. In: Flensburg: Kraftfahrt-Bundesamt; 2013

25. Stentzel U, Piegsa J, Fredrich D, Hoffmann W, van den Berg N. Accessibility of general practitioners and selected specialist physicians by car and by public transport in a rural region of Germany. BMC Health Serv Res. 2016; 16(1):587.

26. IQWiG. Health care in Germany. In: Institute for quality and efficiency in health care. Germany: IQWiG; 2015.

27. Statistisches Amt Mecklenburg-Vorpommern. Bevölkerung nach Alter und Geschlecht in Mecklenburg-Vorpommern 2010. In: . Schwerin: Statistisches Amt Mecklenburg-Vorpommern. p. 2011.

28. Laufende Raumbeobachtung des BBSR [http://www.bbsr.bund.de/BBSR/DE/ Raumbeobachtung/Raumabgrenzungen/SiedlungsstrukturelleGebietstypen/ Regionstypen/regionstypen.html].

29. John U, Greiner B, Hensel E, Lüdemann J, Piek M, Sauer S, Adam C, Born G, Alte D, Greiser E, et al. Study of health in Pomerania (SHIP): a health examination survey in an east German region: objectives and design. Soz Praventivmed. 2001;46:186-96.

30. Winkler J: Die Messung des sozialen Status mit Hilfe eines Index in den Gesundheitssurveys der DHP. In: Messung soziodemographischer Merkmale in der Epidemiologie. Ahrens W., Bellach B., Jöckel K.-H.; 1998: 69-74.

31. Winkler J, Stolzenberg H. Der Sozialschichtindex im Bundesgesundheitssurvey. Das Gesundheitswesen. 1999, Sonderheft;2(61): 178-83.

32. Andersen R. A behavioral model of families use of health services. 1968;25

33. Andersen RM, Newman JF. Societal and individual determinants of medical care utilization in the United States. Milbank Memorial Fund Quarterly Health and Society. 1973;51(1):95-124.

34. Andersen RM. Revisiting the behavioral model and access to medical care: does it matter? J Health Soc Behav. 1995;36:1-10.

35. Dijkstra EW. A note on two problems in connexion with graphs. Numer Math. 1959:1(1):269-71.

36. Möhring RH. Verteilte Verbindungssuche im öffentlichen Personenverkehr: Graphentheoretische Modelle und Algorithmen. In. Berlin: Technische Universität Berlin; 1999

37. Lampert T, Kroll L, Muters S, Stolzenberg H. Measurement of socioeconomic status in the German health interview and examination survey for adults (DEGS1). Bundesgesundheitsblatt Gesundheitsforschung Gesundheitsschutz. 2013;56(5-6):631-6.

38. Goovaerts P. Visualizing and testing the impact of place on late-stage breast cancer incidence: a non-parametric geostatistical approach. Health \& place. 2010;16(2):321-30.

39. Gumpertz ML, Pickle LW, Miller BA, Bell BS. Geographic patterns of advanced breast cancer in Los Angeles: associations with biological and sociodemographic factors (United States). Cancer causes \& control : CCC. 2006;17(3):325-39.

40. Kim M, Ren J, Tillis W, Asche CV, Kim IK, Kirkness CS. Explaining the link between access-to-care factors and health care resource utilization among individuals with COPD. International journal of chronic obstructive pulmonary disease. 2016;11:357-67.

41. Tarlov E, Zenk SN, Campbell RT, Warnecke RB, Block R. Characteristics of mammography facility locations and stage of breast cancer at diagnosis in Chicago. Journal of urban health : bulletin of the New York Academy of Medicine. 2009;86(2):196-213.

42. Siewert U: Querschnittserhebung zu Determinanten der Inanspruchnahme und der Erreichbarkeit niedergelassener Ärzte für über 60-Jähriger in ländlichen und städtischen Regionen Vorpommerns. In. Greifswald; 2014.

43. Gieseler V, Scheer D, Huysmann A, Motz W, Blank W, Kempka J, Marschall P, Fleßa S. Initiative Leben und Wohnen im Alter. In. Technologiezentrum Fördergesellschaft mbH Vorpommern: Greifswald; 2015.

44. Steinrück $B$, Küpper P. Mobilität in ländlichen Räumen unter besonderer Berücksichtigung bedarfsgesteuerter Bedienformen des ÖPNV (No.02/2010). Arbeitsberichte aus der vTI-Agrarökonomie; 2010.

45. Lampert T, Kroll LE. Income differences in health and life expectancy cross-sectional and longitudinal findings of the German socio-economic panel (GSOEP). Gesundheitswesen (Bundesverband der Arzte des Offentlichen Gesundheitsdienstes (Germany)). 2006;68:219-30.

46. Hoebel J, Richter M, Lampert T. Social status and participation in health checks among men and women in Germany - results from the German Helath update (GEDA), 2009 amd 2010. Deutsches Arzteblatt international. 2013;110(41):679-85

47. Richter M, Brand H, Rössler G. Sozioökonomische Unterschiede in der Inanspruchnahme von Früherkennungsuntersuchungen und Maßnahmen der Gesundheitsförderung in NRW. Gesundheitswesen (Bundesverband der Arzte des Offentlichen Gesundheitsdienstes (Germany)). 2002;64:417-23.

48. Röckl-Wiedmann I, Meyer N, Fischer R, Laubereau B, Weitkunat R, Überla K. Schichtspezifische Inanspruchnahme medizinischer Leistungen und Vorsorgeverhalten in Bayern: Ergebnisse einer repräsentativen Bevölkerungsbefragung. Soz- Präventivmed. 2002;47:307-17.

49. Tian N, Goovaerts P, Zhan FB, Chow TE, Wilson JG. Identifying risk factors for disparities in breast cancer mortality among African-American and Hispanic women. Women's health issues: official publication of the Jacobs Institute of Women's Health. 2012;22(3):e267-76.

50. Begley C, Basu R, Lairson D, Reynolds T, Dubinsky S, Newmark M, Barnwell F, Hauser A, Hesdorffer D. Socioeconomic status, health care use, and outcomes: persistence of disparities over time. Epilepsia. 2011;52(5):957-64.

51. Turrell G, Oldenburg BF, Harris E, Jolley D. Utilisation of general practitioner services by socio-economic disadvantage and geographic remoteness. Aust N Z J Public Health. 2004;28(2):152-8.

52. Din GY, Zugman Z, Khashper A. Utilization of primary and secondary medical care among disadvantaged populations: a log-linear model analysis. Global journal of health science. 2014;6(5):9-21.

53. Yom Din G, Zugman Z, Khashper A. The impact of preventive health behaviour and social factors on visits to the doctor. Israel journal of health policy research. 2014;3(1):41.

54. Kolk AM, Hanewald GJ, Schagen S, Gijsbers van Wijk CM. Predicting medically unexplained physical symptoms and health care utilization. A symptom-perception approach. J Psychosom Res. 2002;52(1):35-44.

55. Billinghurst $B$, Whitfield $M$. Why do patients change their general practitioner? A postal questionnaire study of patients in Avon. Br J Gen Pract. 1993;43:339-8

56. Fülöp $G$, Kopetsch T, Schöpe P. Einzugsbereiche von Arztpraxen und die Rolle der räumlichen Distanz für die Arztwahl der Patienten. 2009. [http:// www-v156.rz.uni-mannheim.de/fileadmin/user_upload/pigorsch/pdf/ Einzugsbereiche_von_Arztpraxen_Beta_Kopetsch.pdf].

57. Siewert U. Querschnitterhebung zu Determinanten der Inanspruchnahme und der Erreichbarkeit niedergelassener Ärzte für über 60-Jährige in ländlichen und städtischen Regionen Vorpommerns. Greifswald: Universitätsmedizin Greifswald; 2014.

\section{Ready to submit your research? Choose BMC and benefit from:}

- fast, convenient online submission

- thorough peer review by experienced researchers in your field

- rapid publication on acceptance

- support for research data, including large and complex data types

- gold Open Access which fosters wider collaboration and increased citations

- maximum visibility for your research: over $100 \mathrm{M}$ website views per year

At BMC, research is always in progress.

Learn more biomedcentral.com/submissions 